\title{
Kelengkapan Rekam Medik Kasus Kekerasan Fisik akibat Tindak Pidana di RSUP Prof. Dr. R. D. Kandou Periode September 2017- Agustus 2018
}

\author{
${ }^{1}$ Cherryl A. Lumentut, ${ }^{2}$ Erwin G. Kristanto, ${ }^{2}$ James F. Siwu \\ ${ }^{1}$ Program Studi Pendidikan Dokter Fakultas Kedokteran Universitas Sam Ratulangi Manado \\ ${ }^{2}$ Bagian Ilmu Kedokteran Forensik dan Medikolegal Fakultas Kedokteran Universitas Sam \\ Ratulangi Manado \\ Email: lumentutcherryl@gmail.com
}

\begin{abstract}
Complete medical record is clearly important to health service of a hospital. In cases of violence, medical records play a significant role in law enforcement. Prof. Dr. R. D. Kandou Hospital is categorized as type A service hospital that has been fully accredited in 2015. Therefore, its medical personnels should be responsible for the completeness of each patient's medical record, especially of violence cases. This study was aimed to determine the completeness of physical violence cases' medical records due to criminal acts at Prof. Dr. R. D. Kandou Hospital in the period of September 2017-August 2018. This was a descriptive retrospective study. The results obtained as many as 40 cases of physical violence due to criminal acts. The medical record completeness of physical violence cases due to criminal acts were as follows: in Emergency Care $40 \%$, inpatients 12\%, surgery $58.82 \%$, anesthesia/ sedation $45.45 \%$, blood transfusion $66.67 \%$, and informed consent $96.87 \%$. Conclusion: In physical violence cases due to criminal acts, the medical record completeness with informed consent had higher percentage than the other medical record documents.
\end{abstract}

Keywords: completeness of medical record, physical violence cases

\begin{abstract}
Abstrak: Kelengkapan rekam medik merupakan hal penting dalam pelayanan kesehatan dari suatu rumah sakit. Dalam kasus kekerasan, rekam medik berperan dalam penegakan hukum. RSUP Prof. Dr. R. D. Kandou sebagai rumah sakit pelayanan tipe A yang telah terakreditasi paripurna pada tahun 2015, sudah seharusnya kelengkapan rekam medis bagi setiap pasien menjadi tanggung jawab tenaga medis terutama rekam medik kasus kekerasan yang ada di RSUP. Prof. Dr. R. D. Kandou. Penelitian ini bertujuan untuk mengetahui kelengkapan rekam medik kasus kekerasan fisik akibat tindakan pidana di RSUP Prof. Dr. R. D. Kandou periode September 2017 - Agustus 2018. Jenis penelitian ialah deskriptif retrospektif. Hasil penelitian mendapatkan sebanyak 40 kasus kekerasan fisik akibat tindak pidana. Secara keseluruhan kelengkapan rekam medik pada kasus kekerasan fisik akibat tindak pidana di Instalasi Rawat Darurat sebesar $40 \%$, rawat inap $12 \%$, tindakan operatif $58,82 \%$, tindakan anestesi/sedasi $45,45 \%$, transfusi darah $66,67 \%$, dan informed consent 96,87\%. Simpulan: Pada kasus kekerasan fisik akibat tindakan pidana, kelengkapan rekam medik dengan informed consent memiliki persentase yang lebih tinggi daripada berkas rekam medik lainnya.
\end{abstract}

Kata kunci: kelengkapan rekam medik, kasus kekerasan fisik

Kelengkapan rekam medik merupakan hal yang penting dalam pelayanan kesehatan karena memengaruhi proses pelayanan oleh petugas medis dan kualitas pelayanan suatu rumah sakit. Informasi yang bermanfaat dalam meningkatkan mutu pelayanan kese- hatan di rumah sakit perlu didukung oleh adanya data yang lengkap, akurat, tepat waktu, dan dapat dipercaya. Pemanfaatan informasi rekam medik dapat digunakan baik untuk kepentingan internal maupun eksternal rumah sakit. ${ }^{1}$ 
Salah satu kepentingan eksternal yaitu untuk pengadilan dapat digunakan visum et repertum (VeR) termasuk pasien dengan kasus kekerasan. Kekerasan itu sendiri sudah sering ditemukan bahkan terjadi di berbagai kalangan, seperti kasus kekerasan yang dilakukan oleh seorang siswa terhadap gurunya di SMAN 1 Torjun pada 2 Februari 2018. ${ }^{2}$ Berdasarkan pernyataan dari Kepala Dinas Pemberdayaan Perempuan dan Perlindungan Anak sampai bulan Juli sudah dilaporkankan 80 kasus kekerasan yang terjadi di Sulawesi Utara. ${ }^{3}$ Kedua fakta tersebut membuktikan bahwa kekerasan sudah sering terjadi tanpa memandang usia, status social, maupun jenis kelamin. Krisis nyawa yang diakibatkan oleh kecelakaan lalu lintas (KLL) diperkirakan akan terus berlanjut dikarenakan peningkatan jumlah kendaraan yang terus bertambah dan tidak diimbangi perluasan jalan. Kecelakaan mengakibatkan kerugian material bahkan sampai menelan korban jiwa. Semakin banyak kendaraan yang bersirkulasi di jalan raya maka semakin meningkat risiko terjadinya KKL. ${ }^{4}$

Hubungan kelengkapan rekam medik dan kasus kekerasan itu sendiri sebagaimana yang tertera dalam Manual Rekam medis oleh Konsil Kedokteran Indonesia yaitu rekam medik dapat menjadi pembuktian masalah hukum, disiplin dan etik yang berarti rekam medik merupakan alat bukti tertulis utama yang bermanfaat dalam penyelesaian masalah hukum, disiplin, dan etik. ${ }^{5}$ Rekam medik yang lengkap layak untuk dijadikan alat bukti tertulis pada pasien dengan kasus kekerasan.

RSUP Prof. Dr. R. D. Kandou telah memiliki banyak penghargaan dan dikategorikan sebagai rumah sakit pelayanan tipe A yang terakreditasi paripurna pada tahun 2015. ${ }^{6}$ RSUP Prof. Dr. R. D. Kandou mendapatkan akreditasi Joint Commission International (JCI) pada tahun 2018. ${ }^{7}$ Oleh karena itu, kelengkapan rekam medik bagi setiap pasien menjadi tanggung jawab pihak rumah sakit. Penelitian ini bertujuan untuk mengetahui kelengkapan rekam medik kasus kekerasan fisik akibat tindak pidana di RSUP Prof. Dr. R. D. Kandou.

\section{METODE PENELITIAN}

Jenis penelitian ini ialah deskriptif retrospektif dengan menggunakan data sekunder yang diperoleh dari rekam medik pasien kasus kekerasan fisik akibat tindak pidana. Penelitian ini dilakukan di Bagian Ilmu Kedokteran Forensik dan Medikolegal RSUP Prof. Dr. R. D. Kandou Manado.

Populasi penelitian ialah pasien yang mengalami kasus kekerasan fisik akibat tindak pidana di RSUP Prof. Dr. R. D. Kandou. Sampel penelitian ialah data rekam medik kasus kekerasan fisik akibat tindak pidana periode Septem-ber 2017Agustus 2018 yang memenuhi kriteria inklusi. Variabel penelitian mencakup kelengkapan rekam medik kasus kekerasan fisik akibat tindak pidana di Instalasi Gawat Darurat, pasien yang dirawat inap, serta berdasarkan formulir lainnya dan formulir informed consent.

\section{HASIL PENELITIAN}

Hasil penelitian mendapatkan selama periode September 2017 sampai Agustus 2018, terdapat 40 kasus kekerasan fisik akibat tindak pidana. Semua pasien masuk melalui Instalasi Gawat Darurat (IGD). Sebanyak 15 pasien dirawat di IGD dan langsung pulang, namun sebanyak 25 pasien yang di transfer dan dirawat inap di rumah sakit. Pasien yang mendapatkan tindakan lain-lain yaitu sebanyak 17 pasien yang ditatalaksana dengan tindakan operatif, sebanyak 11 pasien yang mendapatkan tindakan anestesi/sedasi dan sebanyak 12 pasien yang mendapatkan tindakan transfusi darah.

Dari 40 rekam medik pasien kasus kekerasan fisik akibat tindak pidana yang masuk melalui IGD RSUP Prof. Dr. R. D. Kandou didapatkan sebesar $60 \%$ rekam medik yang lengkap yaitu 24 pasien dan $40 \%$ rekam medik yang tidak lengkap yaitu 16 pasien.

Jumlah pasien kekerasan fisik akibat tindak pidana yang masuk di IGD yang kemudian dirawat inap ialah 25 pasien. Didapatkan sebesar $88 \%$ rekam medik yang tidak lengkap yaitu 22 pasien dan hanya $12 \%$ rekam medik lengkap yaitu 3 pasien. 
Pada 25 pasien yang dirawat inap, 17 pasien diantaranya dilakukan tindakan operatif. Didapatkan sebesar 58,82\% rekam medik yang lengkap yaitu 10 pasien dan $41,18 \%$ rekam medis tidak lengkap yaitu 7 pasien.

Pada 17 pasien yang dilakukan tindakan operatif, sebanyak 11 pasien diantaranya dilakukan tindakan anestesi/sedasi. Sebesar $54,55 \%$ rekam medik yang tidak lengkap yaitu 6 pasien dan hanya 45,45\% rekam medis lengkap yaitu 5 pasien.

Sebanyak 12 pasien dari kasus kekerasan fisik yang dilakukan transfusi darah. Didapatkan sebesar $66,67 \%$ rekam medik yang lengkap yaitu 8 pasien dan $33,33 \%$ rekam medis yang tidak lengkap yaitu 4 pasien

Semua tindakan yang dilakukan di rumah sakit baik tindakan pemeriksaan, tindakan operatif, anestesi/sedasi, transfusi darah, menjahit dan membersihkan luka, dan lain sebagainya, membutuhkan persetujuan dari pasien atau keluarga yang mewakili pasien. Dari 4 tindakan yang membutuhkan informed consent pada rekam medik pasien kasus kekerasan fisik akibat tindak pidana ditemukan sebesar $96,87 \%$ rekam medik yang lengkap dan hanya $3,13 \%$ rekam medis yang tidak lengkap.

\section{BAHASAN}

Dari 40 rekam medik pasien kasus kekerasan fisik akibat tindak pidana yang masuk melalui IGD RSUP Prof. Dr. R. D. Kandou didapatkan sebesar $60 \%$ rekam medik yang lengkap dan $40 \%$ rekam medik yang tidak lengkap. Definisi Instalasi Gawat Darurat Rumah Sakit menurut Departemen Kesehatan adalah institusi yang memberikan pelayanan penanggulangan penderita rawat darurat yang mencakup suatu rangkaian kegiatan untuk mencegah kematian (life saving) atau cacat yang mungkin terjadi. Bila dihubungkan dengan jumlah formulir rekam medik yang harus diisi di IGD, maka didapatkan bahwa lebih sedikit formulir yang harus diisi di IGD dibandingkan formulir yang harus diisi saat pasien dirawat inap. Perbedaan prosedur pelayanan di IGD yaitu tenaga kesehatan diharuskan untuk mengutamakan pengobatan/tindakan untuk pasien dengan tepat dan cepat sesuai dengan status kegawatan pasien tersebut menyebabkan lebih banyak tenaga kesehatan lebih terpaku pada keselamatan pasien dibandingkan pengisian rekam medik. ${ }^{8}$

Jumlah pasien kekerasan fisik akibat tindak pidana yang masuk di IGD kemudian dirawat inap sebanyak 25 pasien. Sebesar $88 \%$ rekam medis yang tidak lengkap dan hanya $12 \%$ rekam medik yang lengkap. Pengetahuan tenaga medis berperan dalam pengisian rekam medik mengenai aspek-aspek yang harus ada dalam rekam medik. Hasil penelitian Sugiyanto mendapatkan adanya hubungan antara pengetahuan dokter dengan kelengkapan pengisian data rekam medis pada lembar resume pasien. ${ }^{9}$ Sebagai rumah sakit pendidikan seringkali pencatatan rekam medik dibuat oleh co-assistent mahasiswa program profesi dokter. Hal ini didelegasikan oleh dokter yang bertanggung jawab atas pasien yang kemudian harus diperiksa kembali kebenaran dan kelengkapan rekam medik oleh dokter yang mendelegasikan penulisan rekam medis tersebut. Hasil pencatatan rekam medis yang didelegasikan lalu kemudian tidak diperiksa kembali oleh dokter yang bertanggung jawab terhadap pasien karena kesibukan dokter atau lain hal merupakan salah satu faktor penyebab ketidaklengkapan rekam medis.

Pada 25 pasien yang dirawat inap, 17 pasien diantaranya dilakukan tindakan operatif. Dari 17 rekam medik pasien yang dilakukan tindakan operatif didapatkan sebesar 58,82\% rekam medis yang lengkap dan $41,18 \%$ rekam medis yang tidak lengkap. Pada pengamatan ditemukan bahwa dari semua formulir yang harus diisi, hanya formulir monitoring risiko jatuh saja yang tidak terisi sehingga dapat disimpulkan bahwa formulir lainnya dinilai lebih penting untuk diisi dibandingkan monitorring risiko jatuh, padahal semua formulir memiliki dampak dan manfaat masingmasing. Fungsi formulir monitoring risiko jatuh berdasarkan standar akreditasi rumah sakit yang ditetapkan oleh Komisi Akredi- 
tasi Rumah Sakit pada sasaran 6 yaitu rumah sakit melaksanakan upaya mengurangi risiko cedera akibat pasien jatuh. ${ }^{10}$

Pada 17 pasien yang dilakukan tindakan operatif, sebanyak 11 pasien diantaranya dilakukan tindakan anestesi/sedasi. Dari 11 rekam medik pasien tersebut didapatkan sebesar $54,55 \%$ rekam medik yang tidak lengkap dan hanya $45,45 \%$ rekam medik yang lengkap. Formulir yang tidak diisi yaitu asuhan keperawatan perianestesia dan asuhan keperawatan perioperatif, maka yang berperan dalam ketidaklengkapan pengisian formulir ini yaitu kurangnya ketelitian dari perawat. Seorang perawat juga harus teliti dalam pengisian data dokumen rekam medik karena setiap tindakan yang dilakukan oleh perawat harus dicatat dalam dokumen tersebut. ${ }^{1}$

Pada 12 pasien dengan kasus kekerasan fisik yang dilakukan transfusi darah didapatkan sebesar $66,67 \%$ rekam medik yang lengkap dan hanya 33,33\% rekam medis yang tidak lengkap. Hal yang menyebabkan tidak lengkapnya formulir catatan pelaksanaan transfusi darah yaitu pasien yang sudah bersedia menerima transfusi darah tetapi akhirnya tidak mendapatkan tindakan tersebut karena kondisi pasien yang sudah stabil. Jadi walaupun terdapat formulir persetujuan tindakan transfusi darah bagi pasien itu, namun formulir catatan pelaksanaan transfusi darah tidak ditemukan karena pelaksanaan akhirnya tidak dilakukan.

Semua tindakan yang dilakukan di rumah sakit baik pada tindakan pemeriksaan, tindakan operatif, anestesi/sedasi, transfusi darah, menjahit dan membersihkan luka dan lain sebagainya, membutuhkan persetujuan dari pasien atau keluarga yang mewakili pasien. Dari 4 tindakan yang membutuhkan informed consent pada rekam medik pasien kasus kekerasan fisik akibat tindak pidana ditemukan sebesar 96,87\% rekam medik yang lengkap dan hanya $3,13 \%$ rekam medik yang tidak lengkap.

Tindakan lain-lain berupa pemeriksaan radiologi, laboratorium dan lainnya harus segera dilakukan agar dokter dapat lang- sung mengetahui diagnosis pasti untuk kepentingan tatalaksana yang harus dilakukan secepat mungkin mengingat kebanyakan pasien kasus kekerasan fisik datang dengan keadaan kritis. Sebagai rumah sakit rujukan di Indonesia bagian Timur, maka banyak pasien termasuk pasien kekerasan fisik yang dirujuk melalui IGD RSUP. Prof. Dr. R. D. Kandou. Hasil penelitian Sugiyanto menjelaskan terdapat hubungan beban kerja dokter dengan kelengkapan pengisian data pada lembar rekam medik pasien. Semakin besar jumlah pasien maka seorang dokter tentunya harus mengisi jumlah dokumen yang semakin banyak, sehingga waktu dokter tidak cukup untuk melengkapi semuanya. ${ }^{9}$ Adanya beban kerja yang banyak dan waktu untuk tatalaksana harus secepatnya mungkin menyebabkan formulir persetujuan tindakan tidak semua terisi.

\section{SIMPULAN}

Berdasarkan hasil penelitian ini dapat disimpulkan bahwa terdapat lebih banyak rekam medik yang lengkap pada pasien di Instalasi Gawat Darurat, tindakan operatif, tindakan transfusi darah, dan formulir informed consent serta lebih banyak rekam medik yang tidak lengkap pada pasien yang dirawat inap dan tindakan anestesi/sedasi. Formulir informed consent memiliki persentase kelengkapan yang paling tinggi dan rekam medik pasien rawat inap memiliki persentase kelengkapan yang paling rendah.

Walaupun informasi yang tercantum dalam rekam medik kasus kekerasan fisik dinilai lengkap memuat informasi yang berkaitan untuk penegakan hukum tindak pidana kekerasan, namun secara keseluruhan masih banyak formulir yang tidak lengkap sesuai dengan ketentuan RSUP Prof. Dr. R. D. Kandou.

\section{SARAN}

Disarankan agar dilakukan penelitian lebih lanjut dengan menilai kualitas dari rekam medik. Bagi pihak rumah sakit disarankan untuk meningkatkan kedisiplinan dalam proses manajemen rumah sakit 
dari proses analyzing agar lebih teliti dalam penilaian kembali rekam medis yang tidak lengkap untuk kemudian dapat dilengkapi dan untuk proses coding untuk dikoreksi agar lebih mudah untuk mendapatkan rekam medis yang tepat sesuai ketentuan coding berdasarkan ICD 10.

\section{DAFTAR PUSTAKA}

1. Rahmadhani IS, Sugiarsi S, Pujihastuti. Faktor penyebab ketidaklengkapan dokumen rekam medis pasien rawat inap dalam batas waktu pelengkapan di Rumah Sakit Umum Daerah Dr. Moewardi Surakarta. Jurnal Kesehatan. 2008;II(2):82-8.

2. Farmita AR (reporter). Penganiayaan guru oleh siswa di Sampang, pelaku boleh ikut UN. Available from: https:// nasional.tempo.co/read/1056897/penga niayaan-guru-oleh-siswa-di-sampangpelaku-boleh-ikut-un

3. 80 kasus kekerasan masuk DP3A. Available from: http://manadopostonline.com/ $\mathrm{read} / 2018 / 07 / 14 / 80-$ Kasus-KekerasanMasuk-DP3A/40603

4. Putri DP. Perbandingan karakteristik kekerasan yang terjadi terhadap anak di sekolah pada Sekolah Menengah Atas dan Sekolah Menengah Kejuruan di Kota Tegal [Karya Tulis Ilmiah]. Semarang: Universitas Diponegoro;
2015.

5. Manual Rekam Medis oleh Konsil Kedokteran Indonesia tahun 2008. Available from: http://gamel.fk.ugm.ac.id/pluginfile. php/48290/mod_resource/content/1/62 _MANUAL_REKAM_MEDIS.pdf

6. RSUP Prof. Dr. R. D. Kandou. Available from: https://www.rsupkandou.com/basic/inf $\mathrm{o} / 128$

7. Kementerian Kesehatan republilk Indonesia. Direktorat Jenderal Pelayanan Kesehatan. RSUP Prof. Dr. R. D. Kandou Manado resmi terakreditasi internasional JCI. Available from: http:// yankes.kemkes.go.id/read-rsup-prof-drr-d-kandou-manado-resmiterakreditasi-internasional-jci4487.html

8. Ervafira A. Perbedaan kelengkapan pengisian rekam medis antara instalasi rawat jalan dan instalasi rawat darurat di poli bedah RSUP Dr. Kariadi Semarang [Karya Tulis Ilmiah]. Semarang: UNDIP; 2012

9. Ridho KM, Rosa EM, Suparniati E. Analisis faktor-faktor yang mempengaruhi kepatuhan pengisian rekam medis di Rumah Sakit Gigi dan Mulut Pendidikan UMY. JMMR. 2013;2(2):1-18.

10. Komisi Akreditasi Rumah Sakit. Standar Nasional Akreditasi Rumah Sakit (1st ed). Jakarta: Kemenkes RI, 2017; p. 56. 